\title{
DIRETRIZES CURRICULARES PARA O CURSO DE PEDAGOGIA NO BRASIL: A GESTÃO DA EDUCAÇÃO COMO GÉRMEN DA FORMAÇÃO
}

\author{
Naura Syria Carapeto Ferreira*
}

\begin{abstract}
RESUMO: Este artigo analisa as Diretrizes Curriculares para o Curso de Pedagogia exaradas pelo Conselho Nacional de Educação. Discute algumas questōes de princípio e de concepção sobre as políticas de formação de profissionais da educação nas diretrizes e a gestão da educação que se constitui o gérmen de sua formação. Toma-se como referência a tese de que a relevante e inquestionável importância da formação do profissional da educação se situa na responsabilidade e no compromisso da formação para a cidadania, como reza a Constituição da República Federativa do Brasil e a Carta Magna da Educação Brasileira. É este o compromisso da gestão da educação exercida pelo professor se fazendo em ação na sala de aula, por conter "em gérmen" o espírito e o conteúdo do projeto político e pedagógico que expressa os compromissos e o norte da escola por meio da gestão do ensino, da gestão da classe, da gestão das relaçóes, da gestão do processo de aquisição do conhecimento, enfim, da gestão da formação para a cidadania. Tal concepção perpassa, de forma implícita e explícita, todo o texto das diretrizes.
\end{abstract}

Palavras-chave: Pedagogia. Diretrizes Curriculares de Pedagogia. Gestão da educação. Formação. Política educacional.

\section{CurRiculum guidelines For PEDAGOgY COURSE IN BRAZIL: THE ADMINISTRATION OF THE EDUCATION AS SOURCE OF TRAINING}

ABSTRACT: This article analyzes the Curriculum Guidelines for the Pedagogy Course, which were developed by the National Council of Education. It discusses some conception and principle issues on the strategies of the training of education professionals

Doutora em Educação, professora titular do Programa de Pós-Graduação da Universidade Tuiuti (PR) e professora (aposentada) da Universidade Federal do Paraná (UFPR). E-mail: naura@uol.com.br 
according to these Guidelines and the administration of education that is the source of such training. Its reference is the theory according to which the relevant and unquestionable importance of the training of education professionals is placed under the responsibility and commitment of citizenship training, as stated in the Constitution of the Federal Republic of Brazil and in the Charter of Brazilian Education. This is the commitment of the education administration exercised by the teacher acting in classrooms. It contains the spirit and the contents of the pedagogic political project that expresses the commitments and direction of school through the administration of teaching, of classrooms, of relationships, of the process of knowledge acquisition, that is, the administration of citizenship training. Such conception is implicitly and explicitly present in the whole text of the Guidelines.

Key words: Pedagogy. Pedagogy Curriculum Guidelines. Education administration. Training. Education policy.

\section{Introdução}

$E$

xarada a Resolução CNE/CP n. 1, de 15 de maio de 2006, que institui as Diretrizes Curriculares Nacionais para o Curso de Graduação em Pedagogia, diversas e diferenciadas interpretações entrecruzam-se no cenário nacional, evidenciando diversos e diferenciados referenciais históricos e teóricos. Reconstitui-se um debate rico, porque argumentativo, que contribui para sínteses mais apuradas sobre a formação do profissional da educação - responsável pela formação da cidadania $^{1}$ - com o intuito de aprofundar e consolidar as reflexões a respeito dessa formação. Constituem-se em tendências que se confrontam em debates, fundadas em projetos políticos e perspectivas históricas diferenciadas, quer defendendo uma prioridade, quer outra.

Entretanto, todas têm em comum um mesmo objetivo, a qualidade da formação da cidadania do povo brasileiro, para a qual se debate sobre e reivindica qual seria a melhor formação dos profissionais da educação. Assim, a centralidade da formação dos profissionais da educação vem sendo reafirmada como uma prioridade para políticas públicas responsáveis.

A formação dos profissionais da educação, sua profissionalização e o exercício desses profissionais no Brasil acumulam uma história de lutas, conflitos e de muito empenho e dedicação desses profissionais, 
apesar da não-valorização e da falta de condições devidas e necessárias à qualidade da sua formação e do seu trabalho profissional, por parte do Poder Público. Em contrapartida, com a grande expansão das redes de ensino e dos cursos nos mais diversos formatos e modalidades, em curto espaço de tempo, e a ampliação conseqüente da necessidade de profissionais, a formação destes não logrou, ainda, por estudos, pesquisas e avaliaçôes realizados, prover o ensino com profissionais de qualidade, muitas vezes nem suficientes.

Por essas razões a formação dos profissionais da educação tem se constituído num grande desafio para as políticas públicas educacionais em nosso país, de porte continental, porém considerado de periferia mundial, que não consegue atender às demandas locais e é "bombardeado" pelas determinações internacionais de toda ordem.

Em boa hora, portanto, é promulgada a referida resolução, que não só institui as diretrizes, mas exige reflexão rigorosa, oportuniza o debate e a tomada de decisóes necessárias, pois se sabe que de uma boa e sólida formação de qualidade ${ }^{2}$ dos profissionais da educação e de uma boa e sólida gestão da educação dependerão a vida futura de todos que pela escola passarem. Tal é a importância desta formação pela qual tanto se luta, historicamente, em todos os espaços possíveis.

Por essas razões, pretendo discutir algumas questões de princípio e de concepção sobre as políticas de formaçãao de profissionais da educação, nas Diretrizes Curriculares Nacionais para o Curso de Graduação em Pedagogia, e a gestão da educação que se constitui o gérmen de sua formação. Esta via de raciocínio toma como referência a tese de que a relevante e inquestionável importância da formação do profissional da educação se situa na responsabilidade e no compromisso - que é, em primeira ordem, do Poder Público - da formação para a cidadania, como reza a Constituição da República Federativa do Brasil ${ }^{3}$ e a Carta Magna da Educação Brasileira. ${ }^{4}$

Defendo que a verdadeira cidadania e a verdadeira formação de profissionais da educação são indissociáveis e, por isso, ambas necessitam acontecer à luz dos princípios constitucionais que necessitam reger as políticas públicas educacionais de formação dos profissionais que formam para a verdadeira cidadania - que possa superar o individualismo ${ }^{5}$ imperante e acirrado -, pautada nos ideais de solidariedade humana (Brasil, Lei n. 9.394, art. 20, 1996), justiça social e fraternidade, 
Diretrizes curriculares para o curso de pedagogia no Brasil...

a fim de que se possa, efetivamente, "construir uma sociedade livre, justa e solidária” (Brasil, art. 30 - I - 1988 [2006]).

As diretrizes curriculares e a gestão da educação como gérmen da formação dos profissionais da educação

Compreendendo que a teoria não reduz a "realidade ao que existe", e que, seja qual for o modo como é concebida e considerada, tem de ser encarada como um campo de possibilidades, a tarefa da teoria consiste, precisamente, em definir e avaliar a natureza e o âmbito das alternativas ao que está empiricamente dado. Neste sentido, a análise do que existe se assenta no pressuposto de que a existência não esgota as possibilidades da existência e que, portanto, sempre existem alternativas suscetíveis de superar o que é criticável no que existe, no sentido de superar os limites rumo às possibilidades de tornar melhor o já existente. É o que pretendo realizar neste texto, com o intuito de participar do debate já existente rumo a uma formação humana do profissional da educação.

O Conselho Pleno do Conselho Nacional de Educação exarou a Resolução CNE/CP n. 1, de 15 de maio de 2006, que institui as Diretrizes Curriculares Nacionais para o Curso de Graduação em Pedagogia, licenciatura, "definindo princípios, condições de ensino e de aprendizagem, procedimentos a serem observados em seu planejamento e avaliação pelos órgãos do sistema de ensino e pelas instituições de educação superior no país, nos termos explicitados nos Pareceres n. 5/2005 e 3/2006".

Essa resolução ratifica uma posição já fundamentada nos pareceres acima mencionados e reacende o desafio do debate e da compreensão sobre a formação dos profissionais da educação, visto que as Diretrizes para o Curso de Pedagogia se constituem numa política exarada pelo Conselho Nacional de Educação (CNE), o qual dá o norte para a formação dos profissionais da educação responsáveis pela formação da cidadania.

$\mathrm{O}$ artigo $2^{\circ}$ da resolução especifica que estas "Diretrizes Curriculares para o Curso de Pedagogia aplicam-se à formação inicial para o exercício da docência na Educação Infantil e nos anos iniciais do Ensino Fundamental, nos cursos de Ensino Médio, na modalidade 
Normal e, em cursos de Educação Profissional na área de serviços e apoio escolar, bem como nas áreas nas quais sejam previstos conhecimentos pedagógicos", expressando o argumento exposto no Parecer CNE/ CP n. 5/2005: "A formação oferecida abrangerá, integradamente à docência, a participação da gestão e avaliação dos sistemas e das instituições de ensino em geral, a elaboração, a execução, o acompanhamento de programas e as atividades educativas".

Percebe-se, de forma explícita, a ampla possibilidade de formação e atuação do profissional da educação, assim como a necessidade de uma sólida formação em gestão da educação, compromissada com os princípios constitucionais, sem o que não teria razão de ser. Não se trata de uma formação restrita, tampouco reduz a sua atuação. Bem ao contrário, trata-se, como reza o parecer supracitado, de "observar com especial atenção aos princípios constitucionais e legais: a diversidade sociocultural e regional do país; a organização federativa do Estado brasileiro; a pluralidade de idéias e de concepções pedagógicas, a competência dos estabelecimentos de ensino e dos docentes para a gestão democrática" (Parecer CNE/CP n. 5/2005, p. 6).

No parágrafo $1^{\circ}$ define a docência como

(...) ação educativa e processo pedagógico metódico e intencional, construído em relações sociais, étnico-raciais e produtivas, as quais influenciam conceitos, princípios e objetivos da pedagogia, desenvolvendo-se na articulação entre conhecimentos científicos e culturais, valores éticos e estéticos inerentes a processo de aprendizagem, de socialização e de construção do conhecimento, no âmbito do diálogo entre diferentes visões de mundo.

Tal definição põe em relevo a práxis ${ }^{6}$ como atividade que se produz historicamente, que "renova continuamente e se constitui praticamente - unidade do homem e do mundo, da matéria e do espírito, do sujeito e do objeto, do produto e da produtividade" (Kosik, 1976, p. 202).

Os elementos da definição sobre docência do parágrafo $1^{\circ}$ do artigo $2^{\circ}$ permitem afirmar a determinação da existência humana como elaboração da realidade, verdadeiro sentido da práxis do ser humano, que não é atividade prática contraposta à teoria, mas a abertura deste ser humano para a realidade em geral, cuja dimensão mais essencial é a criação da realidade humano-social. Assim, ação educativa e processo pedagógi- 
Diretrizes curriculares para o curso de pedagogia no Brasil...

co metódico e intencional, construído em relações sociais, étnico-raciais e produtivas, possibilitam a verdadeira formação humana do profissional da educação capaz de desenvolver em seus alunos a cidadania.

A resolução destaca a especificidade da formação inicial para o exercício da docência, mas estende à área de serviços e apoio escolar, bem como às áreas nas quais sejam previstos conhecimentos pedagógicos. Neste sentido, a resolução não fecha possibilidades, bem ao contrário, constitui-se em campo de possibilidades, como a de que a formação pedagógica de todas as demais licenciaturas podem e devem seguir esta normatização nos termos exarados. Esta possibilidade não é uma interpretação subjetiva. Encontra-se expressa nos termos “(...) bem como a outras áreas nas quais sejam previstos conhecimentos pedagógicos”.

Entende-se e louva-se que as Diretrizes Curriculares Nacionais para o Curso de Graduação em Pedagogia, licenciatura, constituam-se a fonte na qual devem "beber" todas as demais formaçōes pedagógicas, pois a pedagogia, entendida como "projeto de inteligência da ação educativa", tal qual define a Enciclopédia Universalis (Hamelini, 1989, p. 101), significa o uso desta capacidade humana - a inteligência - para a tomada de decisões quanto às prioridades - princípios - da formação humana a ser desenvolvida na ação educativa, princípios estes exarados na Constituição Brasileira e na Carta Magna da Educação Brasileira.

Explicita-se, dessa forma, uma unidade de formação pedagógica, no que concerne a princípios e decorrentes definiçôes, necessários de serem desenvolvidos em todos os profissionais da educação, no sentido amplo do termo, isto é, necessários à formação de todos os que trabalham com a educação em todos os níveis e modalidades.

Ao examinar o teor da resolução, pode-se constatar que os itens I e II, que compõem o parágrafo $2^{\circ}$, tratam de conteúdos da gestão da educação, embora não esteja explícito este termo em todos os itens. Se o planejamento, a execução e a avaliação de atividades educativas são concebidos, finalmente, como compromissos do profissional da educação que se forma no curso de pedagogia, a este pedagogo é atribuída a gestão da educação que, entendida como "tomada de decisões, é organização e direção" (Ferreira, 2006a, p. 306), e responsável pela qualidade do ensino que acontece nas instituições escolares.

$\mathrm{O}$ mesmo ocorre nos artigos $3^{\circ}, 4^{\circ}, 5^{\circ}$ e $6^{\circ}$. O parágrafo único do artigo $3^{\circ}$ trata da centralidade da formação e, assim, reza: "I - o 
conhecimento da escola como organização complexa que tem a função de promover a educação para e na cidadania; II - a pesquisa, a análise e a aplicação dos resultados de investigações de interesse da área educacional; III - a participação na gestão de processos educativos e na organização e no funcionamento de sistemas e instituições de ensino". Planejamento, execução e avaliação são componentes da gestão da educação, que abarca a política, o planejamento e a avaliação.

No artigo $4^{\circ}$, de forma explícita, no parágrafo único, está registrado: "As atividades docentes também compreendem participação na organização e gestão de sistemas e instituiçôes de ensino", e nos itens I, II e III, atribuiçōes de planejamento execução, coordenação, acompanhamento e avaliação, como atividades docentes. No artigo $5^{\circ}$, item XII, reza, de forma explícita, que o pedagogo deverá estar apto a "participar da gestão das instituições, contribuindo para elaboração, implementação, coordenação, acompanhamento e avaliação do projeto político-pedagógico"; e de forma implícita em todos os demais 15 itens que compõem esse mesmo artigo.

Vale lembrar que participação do (latim participationis) significa "fazer parte de", "tomar parte em", "fazer saber, informar, anunciar" (Cunha, 1994, p. 584). É fazer parte de uma ação, portanto agindo com, em uma ação que é coletiva. Significa ação conjunta de "um fazer" que também é conjunto e que se destina a todos, significa ação conjunta de "um fazer" que exercita e "ensina a ser". A participação tem, portanto, um caráter instrumental. Isto é, porque, ao se participar, exercita-se um direito de cidadania, responsabiliza-se quem o faz, sobre o que faz e o que necessita ser feito; neste "fazer conjunto" aprende a colaborar com outras pessoas e, portanto, aperfeiçoa-se na convivência com os demais. A participação, portanto, não é somente um processo de atuação de caráter técnico. Possui um caráter e um compromisso social arraigados em valores humanos que são públicos, democráticos, solidários e não podem nem devem refletir interesses individualistas.

A participação do pedagogo, conforme a Resolução CNE/CP n. 1/ 2006 põe em relevo, configura a formação do pedagogo como um gestor, superando, assim, as compreensões restritas e unilaterais.

A importância da gestão na formação do pedagogo é percebida quando Gatti (2003), ao analisar a contribuição das pesquisas sobre a formação de profissionais da educação, indica que há problemas de ges- 
Diretrizes curriculares para o curso de pedagogia no Brasil...

tão, implicados nos processos formativos e no exercício da profissão. As pesquisas põem em questão, sobretudo, o modelo predominante de formação no país, que ainda reflete, embora em tons atenuados, a perspectiva de uma certa elite, que valoriza o enciclopedismo, a excessiva especialização, a fragmentação do conhecimento, em nome do seu necessário aprofundamento, e de uma qualidade cujos componentes não são esclarecidos (Gatti, 2003, p. 389-390).

$\mathrm{O}$ artigo $6^{\circ}$ exara, na letra b do item I: "A aplicação de princípios da gestão democrática em espaços escolares e não-escolares", assim como nos demais itens apresenta conteúdos que pertencem à gestão da educação. Afirmo serem conteúdos da gestão da educação, entendendo com Anísio Teixeira que:

Há no ensino, na função de ensinar, em gérmen, sempre ação administrativa. Seja a lição, seja a classe, envolve tomada de decisóes, envolve administração, ou seja, plano, organização, execução, obediente a meios e técnicas. De modo geral o professor administra a lição ou a classe, ensina, ou seja, transmite, comunica o conhecimento, função antes artística do que técnica, e orienta ou aconselha o aluno, função antes moral, envolvendo sabedoria, intuição, empatia humana. (Teixeira, 1968, p. 17)

Esta conceituação de Anísio Teixeira nos ilumina na compreensão do compromisso da gestão que se faz em sala de aula do exercício da docência e, também, ajuda a compreender a necessária diretividade para a consecução do planejado e organizado em sala de aula. Refere-se à necessária direção do processo educativo que se faz, um só, com os mesmos princípios, valores, conteúdos humanos e "sabedoria" desde a construção coletiva inicial do projeto político-pedagógico, que continua sendo reconstruído a cada momento em que se faz prática, em que a "idéia" se transforma em "ato" e possibilita um novo "pensar" sobre todo este processo de formação humana que se realiza na escola e pelo qual a gestão democrática da educação é responsável.

É a administração - a gestão - fazendo-se em ação na sala de aula, por conter "em gérmen" o espírito e o conteúdo do projeto político-pedagógico que expressa os compromissos e o norte da escola por meio da gestão do ensino, da gestão da classe, da gestão das relaçôes, da gestão do processo de aquisição do conhecimento, "ação educativa e processo pedagógico metódico e intencional, construído em relaçôes sociais, étnico-raciais e produtivas, as quais influenciam conceitos, prin- 
cípios e objetivos da pedagogia, desenvolvendo-se na articulação entre conhecimentos científicos e culturais, valores éticos e estéticos inerentes a processo de aprendizagem, de socialização e de construção do conhecimento, no âmbito do diálogo entre diferentes visōes de mundo", como reza a Resolução CNE/CP n. 1/2006.

A razão de ser da gestão da educação consiste, portanto, a partir dessa definição, na garantia de qualidade do processo de formação humana que possibilitará ao educando crescer e, por intermédio dos conteúdos do ensino, que são conteúdos de vida, hominizar-se, isto é, tornar-se mais humano (Ferreira, 2006b, p. 309).

A ação administrativa a que se referia Anísio não era senão a compreensão de que toda tomada de decisão, seja em que nível ou dimensão for, é sempre uma decisão entre várias alternativas, uma decisão política que terá repercussōes e consequiências de longo alcance sobre o acesso às oportunidades sociais da vida, de cada um, de todos os alunos, em sociedade.

Esta compreensão faz com que se conceba, no professor, no profissional da educação/gestor que faz acontecer, por meio da tomada de decisões, que as políticas educacionais se concretizem no sentido da formação da verdadeira cidadania.

A imprescindibilidade da concepção de gestão na formação dos profissionais da educação

A gestão da educação, no contexto das transformações que se operam no mundo do trabalho e das relações sociais, na "era da globalização" e na chamada "sociedade do conhecimento", atravessa também uma fase de profunda transformação que se constitui num conjunto de diferentes medidas e construçôes que objetivam: "Alargar o conceito de escola; reconhecer e reforçar sua autonomia e promover a associação entre escolas e a sua integração em territórios educacionais mais vastos e adotar modalidades de gestão específicas e adaptadas à diversidade das situações existentes" (Barroso, 2006a, p. 11).

Estas medidas se apoiam na conviçção de que a gestão democrática, a construção coletiva do projeto político-pedagógico e a autonomia da escola são os pressupostos fundamentais para o desenvolvimento da cidadania e, portanto, para a formação do profissional da educação. Para 
Diretrizes curriculares para o curso de pedagogia no Brasil...

tanto, o redimensionamento do compromisso da escola, como agência de formação, não pode vincular-se, meramente, à lógica do mercado de trabalho, mas cumprir sua função social, isto é, cumprir seu papel político-institucional. A gestão democrática da educação, como explicita Dourado (2006a, p. 79), é um

(...) processo de aprendizado e de luta política que não se circunscreve aos limites da prática educativa, mas vislumbra, nas especificidades dessa prática social e de sua relativa autonomia, a possibilidade de criação de canais de efetiva participação e de aprendizado do "jogo" democrático e, conseqüentemente, do repensar das estruturas de poder autoritário que permeiam as relações sociais e, no seio destas, as práticas educativas.

Dourado enfatiza o caráter formador de cidadania que o exercício da gestão democrática possui. Salienta que, ao possibilitar a efetiva participação de todos na construção e gestão do projeto pedagógico e do processo de trabalho que vai formar seres humanos, possibilita, também, a autoformação de todos os envolvidos por e para "leitura", interpretação, debate e posicionamentos que podem fornecer subsídios para novas políticas. Tal aprendizado, que se dá vivenciando o exercício da prática profissional, propicia repensar, também, as estruturas de poder autoritário que ainda existem na ampla sociedade e, conseqüentemente, no âmbito educacional e escolar, ensejando o aprofundamento teórico da gestão democrática necessário à formação do profissional da educação.

Compreende-se, dessa forma, que a concepção de gestão democrática não só está no seio da resolução de forma explícita e implícita, por meio da participação ativa do profissional da educação, mas constitui-se em conteúdo a ser estudado nessa formação pedagógica de forma que se possibilitem ao profissional da educação as atividades específicas da gestão assim como da docência específica. Constitui-se, portanto, a gestão da educação numa concepção que está no cerne da formação e vai garantir ao profissional da educação, em todos os níveis e graus, desenvolver a verdadeira cidadania, por meio de tomadas de decisão sábias e comprometidas com os princípios exarados na Constituição da República Federativa e na Carta Magna da Educação Brasileira. Nessa direção e com essa compreensão, já afirmei em outro lugar que

(...) a gestão democrática da educação é, hoje, um valor já consagrado no Brasil e no mundo, embora ainda não totalmente compreendido e incor- 
porado à prática social global e à prática educacional brasileira e mundial. É indubitável sua importância como um recurso de participação humana e de formação para a cidadania. É indubitável sua necessidade para a construção de uma sociedade mais justa e igualitária. É indubitável sua importância como fonte de humanização. (Ferreira, 2006b, p. 309)

Como conteúdo explícito de formação ou como exercício, por intermédio da participação, constitui-se a gestão democrática da educação, o âmago da qualidade da educação e da formação, posto que ela própria - a gestão - é a responsável pela qualidade da educação.

A resolução acima examinada vem dar cumprimento ao estabelecido na Lei n. 9.294/96, em seu artigo 14, quando estabelece que:

Os sistemas de ensino definirão as normas de gestão democrática do ensino público na educação básica, de acordo com suas peculiaridades e conforme os seguintes princípios: I - participação dos profissionais da educação na elaboração do projeto pedagógico da escola; II - participação das comunidades escolar e local em conselhos escolares ou equivalentes.

A resolução vem ainda dar cumprimento ao que a mesma lei prescreve no artigo 15: "Os sistemas de ensino assegurarão às unidades escolares públicas de educação básica que os integram progressivos graus de autonomia pedagógica e administrativa e de gestão financeira, observadas as normas gerais de direito financeiro público".

Ambos os artigos estabelecem a necessidade de desenvolvimento, organização e exercício da gestão democrática da educação, princípio constitucional ${ }^{7}$ que é validado no artigo $3^{\circ}$ da nossa Carta Magna da Educação Brasileira quando se refere aos princípios que deverão embasar o ensino e a construção da autonomia da escola. Trata-se, portanto, de uma afirmação não causal, mas que representa uma diretiva de organização, que é expressão de uma escolha precisa, de uma decisão que constitui um dos princípios fundamentais do ordenamento educacional. Vai muito além das limitadas e mais modestas exigências de ordem técnica, incidindo profundamente sobre toda a estrutura do Estado e das instituições, modificando-as e contribuindo, sempre que provoque uma divisão de soberania em sentido horizontal, para garantir sobretudo as exigências de caráter democrático desse ordenamento.

Gestão democrática, participação dos profissionais e da comunidade escolar, elaboração do projeto pedagógico da escola, autonomia 
Diretrizes curriculares para o curso de pedagogia no Brasil...

pedagógica e administrativa são os elementos fundantes da gestão da educação em geral e os elementos fundamentais na construção da gestão democrática da escola. Nesta via de raciocínio, vale explicitar algumas definições:

Gestão (do latim gestio-ônis) significa ato de gerir, gerência, administração (Holanda Ferreira, 1999, p. 985). Gestão é tomada de decisão, é organização, é direção. Relaciona-se com a atividade de impulsionar uma organização. É um termo que, historicamente, vem se afirmando no âmbito da administração da educação e no estudo das instituições e organizações, incluindo as educacionais, como sinônimo de administração e que se "instala" no mundo pensante com um sentido mais dinâmico, traduzindo movimento, ação, mobilização, articulação. Embora existam, na literatura, algumas discordâncias quanto à aplicação do conceito de gestão à educação, hoje é preponderante seu emprego para exprimir a responsabilidade pela "direção" e pela garantia de qualidade da educação e do processo educacional em todos os níveis do ensino e da escola.

Superando a concepção taylorista/fordista, que foi a fonte para os estudos de administração da educação, servindo-lhe de norte por longas décadas, a gestão democrática da educação constrói, coletivamente por meio da participação, a cidadania da escola e de seus integrantes.

A gestão da educação, como tomada de decisão, organização, direção e participação, acontece e desenvolve-se em todos os âmbitos da escola, mas, fundamentalmente, na sala de aula, onde concretamente se objetiva o projeto político-pedagógico não só como desenvolvimento do planejado, mas como fonte privilegiada de novos subsídios para novas tomadas de decisões para o estabelecimento de novas políticas.

Como construção coletiva da organização da educação, da escola, das instituiçôes, do ensino, da vida humana, a gestão democrática da educação concretiza-se na prática, quando se tomam decisóes sobre todo o projeto político-pedagógico, sobre as finalidades e os objetivos do planejamento dos cursos, das disciplinas, dos planos de estudo, do elenco disciplinar e sobre os respectivos conteúdos, sobre as atividades dos professores e dos alunos necessárias para a sua consecução, sobre os ambientes de aprendizagem, os recursos humanos, físicos e financeiros necessários, os tipos, modos e procedimentos de avaliação e o tempo para a sua realização. É quando se organiza e se administra coletivamente todo este processo que se está realizando a consubstanciação do projeto político-pedagógico. 
O termo "decisão" (do latim decisione) significa resolução, determinação, sentença, julgamento. Esta é definida, comumente, como uma escolha entre soluções possíveis. Mas esse momento e ato de decidir se assentam num processo subjacente, elaborado a partir do conhecimento e da apreensão da informação necessária e da intencionalidade que lhe dá sentido. É, pois, um processo dinâmico e contínuo referente a um sujeito, individual ou coletivo, no qual esse sujeito que decide interage com o problema - para o qual é necessária a decisão - e o seu contexto, encontrando ou tentando encontrar várias soluções alternativas, escolhendo uma delas fundada em determinados critérios.

A tomada de decisão não corresponde a uma atitude que ocorre em determinado momento. Ela resulta de um processo complexo que se vai construindo por meio de etapas sucessivas que vão, em seqüência, clarificando e tornando consistente o desenvolvimento do processo. O primeiro elemento da estrutura da tomada de decisão é a consciência da necessidade de decidir, que consiste na identificação das situações nas quais se tem de decidir, dos problemas que têm de ser resolvidos e no estudo das alternativas possíveis para tomar a decisão. Quando essa consciência se dá no plano individual, a passagem da decisão para a ação processa-se de forma autoritária, pois se faz necessário fazer obedecer, tentar vencer, ambas atitudes degradantes. A tomada de consciência da necessidade de decidir e o posterior processo de decisão, quando feito no coletivo, propiciam a riqueza de idéias, o debate, o confronto de argumentos diferentes que se constroem no próprio processo coletivo de consciência do problema em questão.

A construção coletiva faz-se na participação, ou seja, quando se compreende e incorpora que participar consiste em ajudar a construir comunicativamente o consenso quanto a um plano de ação coletivo. E isso só é possível por meio do diálogo e do respeito que podem ocorrer e permanecer até nos confrontos, que são divergências necessárias a novas sínteses superadoras de compreensão.

\section{Finalizando para um novo recomeço}

Exaradas as Diretrizes Curriculares para o Curso de Pedagogia, muito tem a se fazer para concretizá-las nas compreensões que emanam do Parecer CNE/CP n. 5/2005 e com a perspectiva de totalidade que esse parecer possui. As exigências da realidade hodierna impóem ao 
Diretrizes curriculares para o curso de pedagogia no Brasil...

pedagogo, hoje, a capacidade de tomar decisões de forma ágil e competente no que concerne ao ensino, à pesquisa e à extensão.

A formação do pedagogo tem, hoje, diretrizes que possibilitam a organização, a estrutura e o funcionamento de um curso comprometido com os princípios constitucionais e os ideais da Carta Magna da Educação Brasileira, sem a fragmentação de habilitações que dispersam os conteúdos da formação. A Resolução CNE/CP n. 1/2006 de forma implícita e explícita reitera os princípios da gestão democrática da educação como elemento fundante da formação do profissional da educação, assegurando esta não-fragmentação por meio da compreensão democrática de totalidade. A gestão educacional é definida

(...) numa perspectiva democrática que integre as diversas atuações e funções do trabalho pedagógico e de processos educativos escolares e não-escolares, especialmente no que se refere ao planejamento, à administração, à coordenação, ao acompanhamento, à avaliação de planos e de projetos pedagógicos, bem como análise, formulação, implementação acompanhamento e avaliação de políticas públicas e institucionais na área da educação. (Parecer CNE/CP n. 5/2005, p. 8)

A gestão democrática da educação como concepção da formação do profissional da educação é, pois, ao mesmo tempo, transparência, autonomia e participação, liderança e trabalho coletivo, representatividade e competência. É compromisso e responsabilidade de garantir que princípios humanos sejam desenvolvidos nos conteúdos de ensino que são conteúdos de vida porque se constituem em instrumentos para uma vida de qualidade para todos em sociedade.

Voltada para um processo de decisão baseado na participação e na deliberação públicas, a gestão democrática expressa um anseio de crescimento dos indivíduos como cidadãos e do crescimento da sociedade como sociedade democrática. Por isso a gestão democrática é a gestão de uma administração concreta (do latim cum crescere), que significa "crescer com", "nascer com". Significa o que "nasce com" e que "cresce com o outro". Esse caráter de origem - genitor - é o horizonte de uma nova cidadania em nosso país, em nossos sistemas de ensino e em nossas instituições escolares, que necessita ser compreendido na formação do profissional da educação.

$\mathrm{O}$ "crescer com" significa, em primeiro lugar, aquilo que Aristóteles explicita quando fala de política e de cidadão como sendo aquele que é 
capaz de exercer o poder, de tomar decisões. O exercício de uma liderança implica alguém que deve responsabilizar-se por atos de deliberação e de decisão. Mas, no espírito da Constituição, da Carta Magna da Educação Brasileira e do movimento que as gerou, essa liderança é colegiada e democrática. Trata-se, pois, da ponte entre o indivíduo e um co-legiado, entre a tomada de decisão e a participação em cujas bases se encontra o diálogo como método e como fundamento.

Portanto, pensar e definir gestão democrática da educação para uma formação humana, como gérmen, como concepção, significa contemplar a formação do profissional da educação de conteúdos e práticas baseados na solidariedade, e nos valores humanos que compóem o construto ético da vida humana em sociedade. E, como estratégia, o único caminho é o diálogo, entendido como "reconhecimento da infinita diversidade do real [que] se desdobra numa disposição generosa de cada pessoa para tentar incorporar ao movimento do pensamento algo da inesgotável experiência da consciência dos outros" (Ferreira, 2000a).

A imprescindibilidade da gestão democrática da educação na formação do pedagogo, do profissional da educação é inconteste e necessária, pois nela está contida a possibilidade de formação de cidadãos justos, porque cônscios, participativos, responsáveis e solidários.

\section{Recebido e aprovado em outubro de 2006.}

\section{Notas}

1. Reitere-se que pelas "mãos" dos profissionais da educação "passam" todas as crianças, jovens e adultos que afluem à escola porque aspiram à formação e à instrumentalização para a vida em sociedade como único canal responsável por fornecer o "passaporte" que os capacite à cidadania e ao mundo do trabalho. Ainda que sejam divergentes e contraditórias as concepções sobre a relação educação e sociedade, educação e produção da existência, educação e atividade econômica, ou sobre que tipo de formação deve ter o profissional da educação, todas elas partilham de algumas questões indubitáveis a esta condição humana que constitui a razão de ser de toda instituição escolar: a formação humana do homem e da mulher em sua ampla dimensão, pessoal e profissional.

2. Qualidade e qualificação são dois elementos constitutivos de uma mesma totalidade. Não existe qualidade sem qualificação e só a qualificação pode produzir qualidade. Uma escola de qualidade para a verdadeira formação da cidadania, por intermédio de um ensino de qualidade, exige um profissional qualificado. Uma formação de qualidade ou sem qualidade exercerá uma influência relevante sobre a possibilidade ou impossibilidade de acesso às oportunidades sociais da vida em sociedade, possibilidade ou impossibilidade de acesso à cidadania.

Educ. Soc., Campinas, vol. 27, n. 97, p. 1341-1358, set./dez. 2006 
Diretrizes curriculares para o curso de pedagogia no Brasil...

3. No artigo $3^{\circ}$ da Constituição da República Federativa do Brasil estão expressos os objetivos fundamentais: I - construir uma sociedade livre, justa e solidária; II - garantir o desenvolvimento nacional; III - erradicar a pobreza e a marginalização e reduzir as desigualdades sociais e regionais; IV - promover o bem de todos, sem preconceitos de raça, sexo, cor, idade e quaisquer outras formas de discriminação.

4. A Constituição da República Federativa Brasileira, em seu Título I, que trata dos Princípios Fundamentais, reza no artigo $1^{\circ}$ : A República Federativa do Brasil, formada pela união indissolúvel dos Estados e Municípios e do Distrito Federal, constitui-se em Estado Democrático de Direito e tem como fundamentos: I - a soberania; II - a cidadania; III - a dignidade da pessoa humana; IV - os valores sociais do trabalho e da livre iniciativa; V - o pluralismo político. E no Capítulo III - da Educação, da Cultura e do Desporto, no artigo 205, exara: A educação, direito de todos e dever do Estado e da família, será promovida e incentivada com a colaboração da sociedade, visando ao pleno desenvolvimento da pessoa, seu preparo para o exercício da cidadania e sua qualificação para o trabalho. E, no artigo 206, do Capítulo III - da Educação, Cultura e do Desporto, incisos VI e VII, exara: gestão democrática do ensino público, na forma da lei; garantia do padrão de qualidade.

5. Em sua obra A democracia na América, Toqueville (1969, p. 49), com lucidez, advertiu sobre os perigos do fenômeno individualista, nome novo para uma idéia mais simples o egoísmo -, e especialmente fecundo em solos ditos democráticos. Em outro lugar escrevi que "o individualismo representa a existência individual sem restriçôes e orientada apenas pelo livre-arbítrio pessoal e por consideraçóes voltadas exclusivamente para o próprio interesse pessoal” (Ferreira, 2000b, p. 215).

6. Karel Kosik (1976, p. 202) explicita que "a práxis na sua essência e universalidade é a revelação do segredo do homem como ser ontocriativo, como ser que cria a realidade (humano social) e que, portanto, compreende a realidade (humana e não-humana, a realidade na sua totalidade)".

7. A Constituição Federal de 1988, no seu artigo 206, determina que "o ensino será ministrado com base nos seguintes princípios: I - igualdade de condiçôes para o acesso e a permanência na escola; II - liberdade de aprender, ensinar, pesquisar e divulgar o pensamento, a arte e o saber; III - pluralismo de idéias e de concepçôes pedagógicas, e coexistência de instituiçóes públicas e privadas de ensino; IV - gratuidade do ensino público em estabelecimentos oficiais; V - valorização dos profissionais do ensino, garantindo, na forma da lei, plano de carreira para o magistério público, com piso salarial profissional e ingresso exclusivamente por concurso público de provas e títulos, assegurando regime jurídico único para todas as instituiçôes mantidas pela União; VI - gestão democrática do ensino público, na forma da lei; VII - garantia do padrão de qualidade".

\section{Referências bibliográficas}

BARROSO, J. O reforço da autonomia das escolas e a flexibilização da gestão escolar em Portugal. In: FerReira, N.S.C. Gestão democrática da educação: atuais tendências, novos desafios. 5. ed. São Paulo: Cortez, 2006a.

\section{BRASIL. Constituiçāo da República Federativa do Brasil: promulgada em 5 de outubro de 1988. São Paulo: Saraiva, 2006.}


BRASIL. Lei n. 9.394 de 20/12/96. Estabelece as Diretrizes e Bases da Educação Nacional. Diário Oficial da União, ano CXXXIV, n. 248, p. 27.833-27.841, 23 dez. 1996.

BRASIL/CNE. Resolução CNE/CP n. 1, de 15 de maio de 2006.

CUNHA, A.G. Dicionário Etimológico Nova Fronteira da Lingua Portuguesa. Rio de Janeiro: Nova Fronteira, 1994.

DOURADO, L.F. A escolha de dirigentes escolares: políticas e gestão da educação. In: Ferreira, N.S.C. Gestão democrática da educação: atuais tendências, novos desafios. 5. ed. São Paulo: Cortez, 2006a.

FERNANDES, F. Tendências e Debates. Folha de S. Paulo, São Paulo, p. 3, 1992.

FERREIRA, N.S.C. Gestão democrática da educação para uma formação humana: conceitos e possibilidades. Em Aberto, Brasília, v. 17, n. 72, fev./jun. 2000a.

FERREIRA, N.S.C. O individualismo na contemporaneidade e o compromisso na administração da educação. In: SERRA, C. Conflito e mestiçagem. Maputo/Moçambique: Universidade Eduardo Mondlane/Livraria Universitária, 2000b.

FERREIRA, N.S.C. A gestão da educação e as políticas de formação de profissionais da educação: desafios e compromissos. In: FERREIRA, N.S.C. Gestão democrática da educação: atuais tendências, novos desafios. 5a ed. São Paulo: Cortez, 2006a.

FERREIRA, N.S.C. Gestão democrática da educação: ressignificando conceitos e possibilidades. In: Ferreira, N.S.C.; AgUiar, M.A. Gestão da educação: impasses, perspectivas e compromissos. 5. ed. São Paulo: Cortez, 2006b.

FERREIRA, N.S.C. Formação continuada e gestão da educação no contexto da "cultura globalizada". In: FerreIrA, N.S.C. Formação continuada e gestão da educação. São Paulo: Cortez, 2006c.

GATTI, B. Formação de professores e a carreira: problemas e movimentos de renovação. Campinas: Autores Associados, 1997.

GATTI, B. Formação de professores, pesquisa e problemas metodológicos. Contrapontos, Itajaí, v. 3, n. 3, 2003. 
Diretrizes curriculares para o curso de pedagogia no Brasil...

GRAMSCI, A. Cartas do cárcere. 2. ed. Rio de Janeiro: Civilização Brasileira, 1978.

HAMELINI, D. Enciclopaedia Universalis: Universalia 1989. Paris: Enciclopaedia Universalis France, 1989.

HOLANDA FERREIRA, A.B. Novo Aurélio século XXI: o dicionário da língua portuguesa. 3. ed. Rio de Janeiro: Nova Fronteira, 1999.

HOUAISS, A. Dicionário Houaiss da lingua portuguesa. Rio de Janeiro: Objetiva, 2001.

KOSIK, K. Dialética do concreto. Rio de Janeiro: Paz \& Terra, 1976.

SAVIANI, D. Pedagogia histórico-crítica: primeiras aproximações. 2. ed. São Paulo: Cortez/Autores Associados, 1991.

SAVIANI, D. Educação: do senso comum à consciência filosófica. São Paulo: Cortez, 1980.

TEIXEIRA, A. Natureza e função da administração escolar. In: Administração escolar - Edição comemorativa do I Simpósio Interamericano de Administração Escolar. Salvador/Bahia/AnPaE, 1968.

TOQUEVIlle, A. Democracy in America. Nova York: Anchor Books, 1969. 